\title{
Primary hepatic embryonal sarcoma masquerading as metastatic ovarian cancer Peter Kullar1 ${ }^{1}$ Christopher Stonard ${ }^{2}$, Neville Jamieson ${ }^{1}$, Emmanuel Huguet ${ }^{1}$, Raaj Praseedom ${ }^{1}$ and Asif Jah*1
}

\author{
Address: ${ }^{1}$ Department of Hepatobiliary and Transplant Surgery, Addenbrooke's Hospital, Cambridge University Hospitals NHS Foundation Trust, \\ Cambridge CB2 2QQ, UK and 2Department of Histopathology, Chesterfield Royal Hospital NHS Foundation Trust, Chesterfield, Derbyshire DE4 \\ 3GJ, UK \\ Email: Peter Kullar - peterkullar@hotmail.com; Christopher Stonard - Christopher.Stonard@chesterfieldroyal.nhs.uk; \\ Neville Jamieson - neville.jamieson@addenbrookes.nhs.uk; Emmanuel Huguet - Emmanuel.Huguet@addenbrookes.nhs.uk; \\ Raaj Praseedom - raaj.praseedom@addenbrookes.nhs.uk; Asif Jah* - asif.jah@addenbrookes.nhs.uk \\ * Corresponding author
}

Published: 23 June 2009

World Journal of Surgical Oncology 2009, 7:55 doi:10.1/86/1477-78/9-7-55

This article is available from: http://www.wjso.com/content/7///55

(C) 2009 Kullar et al; licensee BioMed Central Ltd.

This is an Open Access article distributed under the terms of the Creative Commons Attribution License (http://creativecommons.org/licenses/by/2.0), which permits unrestricted use, distribution, and reproduction in any medium, provided the original work is properly cited.
Received: 9 April 2009

Accepted: 23 June 2009

\begin{abstract}
Background: Hepatic embryonal sarcoma (HES) is a rare but aggressive primary tumor of the liver occurring most frequently in childhood.

Case presentation: We report a case of a 52 year old woman having previously undergone treatment for ovarian serous papillary carcinoma who subsequently presented with a large solitary mass in the liver. Initially this was presumed to be metastasis from the ovarian primary however, on further examination it was shown to be a primary hepatic embryonal sarcoma.
\end{abstract}

Conclusion: Primary liver tumors should be considered in differential diagnoses in patients with ovarian cancer who subsequently present with liver tumors. This is particularly important when there is no direct evidence of recurrence of ovarian cancer.

\section{Background}

Hepatic embryonal sarcoma (HES) is rare primary tumor of the liver usually occurring in childhood. It is generally considered an aggressive tumor with a poor prognosis. Approximately 60 cases have been reported in adults. On the contrary, ovarian carcinoma frequently tends to metastasize to the liver [1]. We report a case of a woman who had previously undergone treatment for bilateral ovarian serous papillary carcinoma and subsequently presented with a large solitary mass in the liver which turned out to be a primary hepatic embryonal sarcoma. We also review the current literature, diagnosis and treatment of HES.

\section{Case presentation}

A 52 year old woman presented with pain and a palpable mass in the right upper quadrant of the abdomen 18 months after completing treatment for ovarian carcinoma. She had previously undergone bilateral salpingooophorectomy and en bloc subtotal colectomy for bilateral high-grade ovarian serous papillary carcinoma infiltrating the sigmoid colon. She also had peritoneal and diaphragmatic seedlings which were debulked concurrently. After the resection, the residual disease was estimated to be less than $0.5 \mathrm{~cm}^{2}$. Subsequently, she received 6 cycles of adjuvant chemotherapy with carboplatin and taxol. Her CA125 level which was elevated at $149 \mathrm{U} / \mathrm{L}$ prior to resec- 
tion later returned to $8 \mathrm{U} / \mathrm{L}$ (normal range $=0-25 \mathrm{U} / \mathrm{L}$ ). Apart from chemotherapy, there was no past history of exposure to radiotherapy or any carcinogens.

During this presentation, the only abnormality on routine hematology and biochemistry was a slightly elevated alkaline phosphatase at $178 \mathrm{U} / \mathrm{L}$ (normal range $=35-130 \mathrm{U} /$ L). The CA125 level was within the reference range (7 U/ L) and no other tumor markers were assayed. A Computerized Tomography (CT) scan revealed a large heterogeneous mass almost completely replacing the right lobe of the liver (Figure 1). No other abdominal, pelvic or lung lesions were identified. Due to the recent history of ovarian cancer, this lesion was suspected to be a solitary metastatic deposit from the ovarian cancer. The liver lesion was not biopsied in order to avoid any needle tract seeding with malignant cells. In the absence of any extrahepatic disease she proceeded to undergo an extended right hepatectomy. During hepatectomy the tumor was found to be adherent to the diaphragm, a part of which was removed en bloc. Post-operatively, she made a good recovery without any complications.

Macroscopically, the tumor was a large, solid and cystic mass that included areas of necrosis and cystic degeneration measuring $18 \times 12 \times 8 \mathrm{~cm}$ (Figure 2). Microscopically, it consisted of pleomorphic malignant spindle cells including rhabdoid and bizarre giant cell forms on a chrondromyxoid stromal background (Figure 3) with focal Periodic Acid Schiff-positive cytoplasmic granules. There was no evidence of epithelial differentiation which excluded the possibility of sarcomatoid hepatocellular

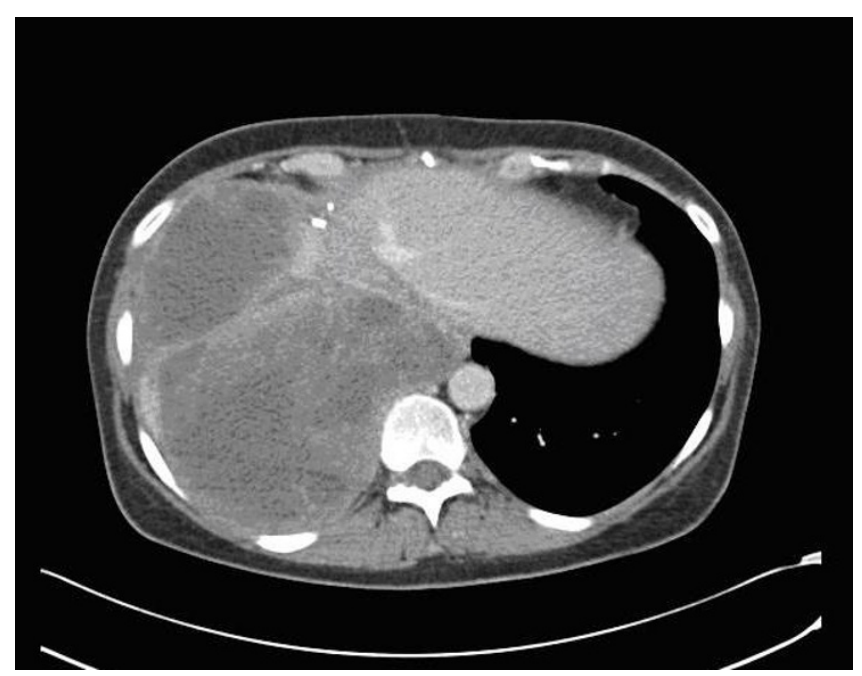

Figure I

Computerized Tomography scan of the abdomen, the tumor is shown to be occupying almost the whole the right lobe of the liver.

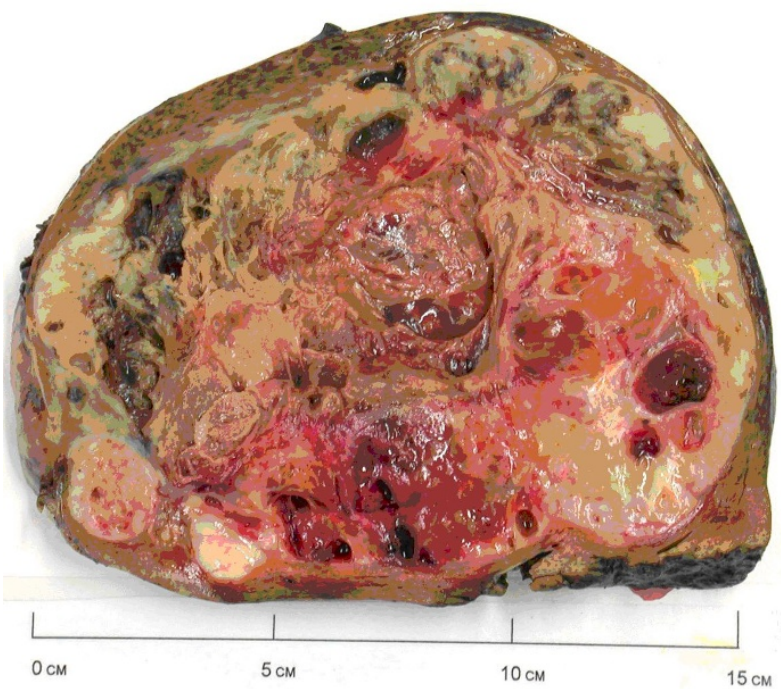

Figure 2

Cut section of the resected hepatic tumor.

carcinoma. Immunohistochemical staining was positive for alpha1-antitrypsin but showed no other indicators of differentiation. This contrasted with the serous papillary morphology of the previously resected ovarian tumor that showed no sarcomatoid areas and no rhabdoid differentiation. The liver tumor was therefore judged to be a second primary rather than a metastatic deposit of the resected ovarian carcinoma. The lesion was classified as primary HES on the basis of its morphology and immunohisto-

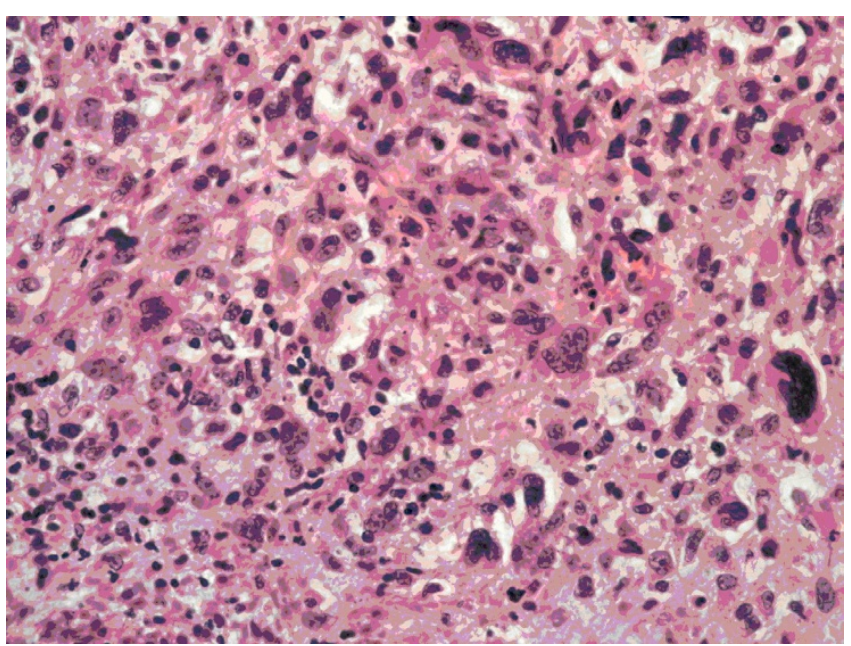

Figure 3

Representative section of a more cellular area showing plump spindle cells, bizarre giant cell forms and scattered apoptotic bodies. (Haematoxylin and eosin stain, photographed at $\times 200$ magnification). 
chemical staining pattern with complete excision noted at the hepatic resection margins.

After remaining well for approximately 6 months she developed progressive shortness of breath and a follow-up CT scan demonstrated a large recurrent tumor contiguous across the right hemithorax and abdomen. A percutaneous biopsy of this mass confirmed the recurrence of the primary hepatic sarcoma. Palliative chemotherapy with ifosfamide and doxorubicin was commenced but had to be stopped after 3 cycles due to severe side effects. She received palliative care for gradual deterioration and died 6 months later.

\section{Discussion}

Ovarian cancer usually presents with widespread intraperitoneal metastasis [2]. A minority of patients present with aggressive disease manifested by liver, lung or brain metastases [3]. An autopsy study of 428 patients with ovarian cancer reported that over $40 \%$ of the patients with ovarian cancer had evidence of liver metastases at the time of death [1]. Amongst the ovarian cancers, the stromal tumors were the most likely histological subtype to metastasize to the liver [1].

Approximately $20 \%$ of the patients with epithelial type of ovarian cancer have been reported to have normal levels of CA125 [4,5]. During second presentation of this patient, the liver function tests were slightly deranged but the CA125 level was within the reference range.

Primary liver sarcomas are rare tumors and represent only $0.2 \%$ of all primary liver tumors [6]. This group includes a number of different histological types such as angiosarcoma, leiomysarcoma, fibrosarcoma, HES, and malignant fibrous histiocytoma [7]. HES are most commonly reported in a pediatric age group, with the peak incidence between the ages of 6 and 10 years. Only 68 cases have been reported in the adult population [8]. Although the etiology of primary liver sarcomas is unclear, there is an increased risk associated with radiation therapy and high doses of alkylators or anthracyclines [8]. The use of Thorotrast as a radiological contrast medium in the 1950s was associated with a very high incidence of hepatic angiocsarcomas [9]. Our patient had received taxol and carboplatin as adjuvant chemotherapy after resection of ovarian cancer but there is no documented association of these agents with development of primary liver sarcomas.

The presentation of liver sarcomas is usually non-specific with symptoms such as abdominal discomfort, anorexia, fever or weight loss [10]. Hepatomegaly may be present with large tumors and liver function tests may be deranged although frank jaundice is rare $[7,10]$. The nonspecific nature of the presenting symptoms makes clinical diagnosis extremely difficult without imaging or biopsy. Although the lesion can be identified on ultrasonography and CT scan, contrast-enhanced Magnetic Resonance Imaging (MRI) scan is the best imaging modality for characterization of primary liver tumors [11].

There are a number of radiographic features which distinguish HES from mesenchymal and other primary hepatic tumors. The myxoid stroma typical of HES appear as large central areas of hypointense signal on T1-weighted images that have high intensity signal on T2-weighted images. Similarly, in the solid peripheral areas of the mass heterogeneous contrast enhancement is seen on both CT and MRI scans [12].

HES have previously been associated with poor outcome. In 1978 Stocker reported a series of 31 patients with HES with mean survival of less that one year after diagnosis [10]. Although radical surgery remains the mainstay of treatment, recent studies have shown improved survival with radical surgery and use of ifosfamide-based multiagent chemotherapy. Almogy et al reported on a series of 8 primary liver sarcomas including two HES managed with surgical resection and adjuvant chemotherapy [13]. Following a liver resection, one patient with a satellite lesion and a second patient with recurrent HES were treated with chemotherapy which led to tumor shrinkage and enabled a second hepatic resection. There is mounting evidence to suggest that neo-adjuvant chemotherapy would allow down-sizing of HES to be followed by resectional surgery $[14,15]$. Bisogno et al identified 17 children with HES treated with initial conservative surgery and multi-agent chemotherapy followed by second-look surgery for any residual disease [14]. They report 70\% (12/ 17) survival at follow up (ranging from 2.4 to 20 years). Thus, in most cases, the accepted standard treatment would consist of aggressive surgical resection with combination chemotherapy either in neoadjuvant or adjuvant setting.

\section{Conclusion}

In this patient HES masqueraded as a metastatic ovarian carcinoma. This case illustrates that the possibility of a primary liver tumor should be considered in patients with ovarian cancer who subsequently present with liver tumors, particularly when there is no direct evidence of recurrence of ovarian cancer.

\section{Consent}

Written informed consent was obtained from the patient's next of kin for publication of this case report and accompanying images. A copy of the written consent is available for review by the Editor-in-Chief of this journal. 


\section{Competing interests}

The authors declare that they have no competing interests.

\section{Authors' contributions}

$\mathrm{PK}$ and $\mathrm{AJ}$ wrote the manuscript, CS reviewed the histology and contributed to the manuscript, NJ, EH critically reviewed the manuscript and RP performed the hepatectomy. All authors read and approved the manuscript.

\section{References}

I. Rose PG, Piver MS, Tsukada Y, Lau TS: Metastatic patterns in histologic variant of ovarian cancer: An autopsy study. Cancer 1989, 64:1508-13.

2. Chobanian N, Dietrich CS: "Ovarian cancer". Surg Clin North Am 2008, 88(2):285-99.

3. Geisler JP, Geisler HE: Brain metastases in epithelial ovarian carcinoma. Gynecol Oncol 1995, 57:246-249.

4. Rosen DG, Wang L, Atkinson JN, Yu Y, Lu KH, Diamandis EP, Hellstrom I, Mok SC, Liu J, Bast RC Jr: Potential markers that complement expression of CAI25 in epithelial ovarian cancer. Gynecol Oncol 2005, 99(2):267-77.

5. Niloff JM, Bast RC Jr, Schaetzl EM, Knapp RC: Predictive value of CA 125 antigen levels in second-look procedures for ovarian cancer. Am J Obstet Gynecol 1985, I 5 I (7):981-6.

6. Primary liver cancer in Japan. Clinicopathologic features and results of surgical treatment. Liver Cancer Study Group of Japan. Ann Surg 1990, 2 I I(3):277-87.

7. Weitz J, Klimstra DS, Cymes K, Jarnagin WR, D'Angelica M, La Quaglia MP, Fong Y, Brennan MF, Blumgart LH, Dematteo RP: Management of primary liver sarcomas. Cancer 2007, I09(7): $|39|-6$.

8. Lenze F, Birkfellner T, Lenz P, Hussein K, Länger F, Kreipe H, Domschke $W$ : Undifferentiated embryonal sarcoma of the liver in adults. Cancer 2008, I I 2(I 0):2274-82.

9. Silpananta P, Illescas FF, Sheldon H: Multiple malignant neoplasms $\mathbf{4 0}$ years after angiography with Thorotrast. Can Med Assoc J 1983, I 28(3):289-92.

10. Stocker JT, Ishak KG: Undifferentiated (embryonal) sarcoma of the liver: report of 3 I cases. Cancer 1978, 42:336-348.

II. Marti-Bonmati L, Ferrer D, Menor F, Galant J: Hepatic mesenchymal sarcoma: MRI findings. Abdom Imaging 1993, I 8(2): I76-I79.

12. Mortelé KJ, Ros PR: Cystic focal liver lesions in the adult: differential CT and MR imaging features. Radiographics 200I, 2I(4):895-9I0.

13. Almogy G, Lieberman S, Gips M, Pappo O, Edden Y, Jurim O, Simon Slasky B, Uzieli B, Eid A: Clinical outcomes of surgical resections for primary liver sarcoma in adults: results from a single centre. Eur J Surg Oncol 2004, 30(4):42I-7.

14. Bisogno G, Pilz T, Perilongo G, Ferrari A, Harms D, Ninfo V, Treuner J, Carli M: Undifferentiated sarcoma of the liver in childhood: a curable disease. Cancer 2002, 94(I):252-7.

15. Kim DY, Kim KH, Jung SE, Lee SC, Park KW, Kim WK: Undifferentiated (embryonal) sarcoma of the liver: Combination treatment by surgery and chemotherapy. J Pediatr Surg 2002, 37:1419-1423.
Publish with Biomed Central and every scientist can read your work free of charge

"BioMed Central will be the most significant development for disseminating the results of biomedical research in our lifetime. "

Sir Paul Nurse, Cancer Research UK

Your research papers will be:

- available free of charge to the entire biomedical community

- peer reviewed and published immediately upon acceptance

- cited in PubMed and archived on PubMed Central

- yours - you keep the copyright

Submit your manuscript here:

http://www.biomedcentral.com/info/publishing_adv.asp
BioMedcentral 